ILTOO Pharma, Medlmmune, Merck Serono, Speakers bureau: GlaxoSmithKline, UCB Pharma

DOI: 10.1136/annrheumdis-2019-eular.8436

\section{SP0037 USING GENETICS IN PERSONALISED MEDICINE IN RHEUMATIC DISEASES}

Anne Barton. University of Manchester, Centre for Musculoskeletal Research, Manchester, United Kingdom

Background: For all treatments available for rheumatoid arthritis (RA), none are effective for all patients. For many drugs, patients are given 3-6 months of treatment before a decision is made regarding efficacy and, for those in whom the treatment does not work, that can be a period of on-going disease activity, exposure to the risk of side effects and possible accumulation of joint damage, all of which impact quality of life. Stratified medicine approaches aim to better target treatments to those most likely to respond. However, currently, CRP/ESR are the only biological markers (biomarkers) routinely used to inform whether therapy is required and RF/ACPA status are often considered.

Objectives: To update in progress of using genomic approaches to inform treatment selection in rheumatoid arthritis

Methods: National and international precision/stratified medicine programmes are investigating whether genetic and epigenetic biomarkers could help in the selection of therapies and progress will be reviewed.

Results: Recent studies have developed new outcome measures to assess treatment efficacy for controlling synovitis, confirming previous findings from genetic studies of heritability. Issues around the best tissue to sample, the predictive ability of a test and confounding factors including adherence will be considered and emerging biomarkers reviewed.

Conclusion: Matching the right treatments to the right patients is the goal of personalised medicine and potential biomarkers are starting to emerge. However caution is required as none have so far been proven to be clinically useful or costeffective.

REFERENCE:

[1] Hensor, et al. Rheumatology 2019; Plat et al, Arthritis and Rheumatol 2019.

Disclosure of Interests: None declared

DOI: 10.1136/annrheumdis-2019-eular.8425

WEDNESDAY, 12 JUNE 2019

18:15:00 - 19:45:00

\section{The riddle of adherence}

\section{SP0038 $\quad$ FACTORS IMPORTANT FOR MEDICAL ADHERENCE}

\section{Bart van den Bemt. Sint Maartensliniek, Netherlands}

Factors important for medical adherence in rheumatic diseases

Disease-modifying antirheumatic drugs (DMARDs) are the cornerstone for the treatment of inflammatory arthritis and fundamental to prevent radiologic progression in patients with rheumatoid/psoriatic arthritis. However, the full benefit of DMARDs can only be achieved if patients follow prescribed treatment regimens. Adherence, or the extent to which patients take medications as prescribed, is however low in chronic medical conditions: approximately $50 \%$ of all people with chronic medical conditions do not adhere to their prescribed medication regimens $[1,2]$. Previous research in patients with rheumatic diseases vary from $30 \%$ to $107 \%$, depending on the used measurement method [7].

Thus, improving adherence to DMARDs could dramatically improve the efficacy of drug therapy in rheumatic diseases and reduce costs. However, so far, interventions designed to improve medication adherence are only partly effective in changing medication-taking behaviour [2-5].

To be able to improve adherence, factors should be known that are associated with medication adherence in RA. This will help us to target non-adherent patients and design interventions to improve adherence. Although several studies have examined factors associated with adherence to treatment with DMARDs, hardly any variable was found to be consistently and strongly related to adherence. [6-7]. Despite this, there is evidence that especially patient's need to take medication, prior DMARD use, patient's self-efficacy and information delivered to the patient might be associated with medication adherence.

Overall, two types of non-adherent behaviour are commonly observed: unintentional (due to forgetfulness, regimen complexity or physical problems) and intentional (when the patient decides not to take the treatment as instructed). In case of intentional non-adherence, the decision to take medication is based on a cost benefit analysis weighing the costs/risks of the treatment against the perceived benefits. This implicates that health care professionals should individually assess patient's (un)intentional barriers to take medication and target medication adherence interventions on patient's individual barriers. Thus, besides tackling (unintentional) practical barriers, such as forgetfulness (with for example reminder services), clinicians should also be sensitive to patient's personal beliefs that might impact medication adherence, and should discuss with their patient any concerns that they raise about prescribed medications. This lecture will give insight in the latest insights in the research of factors important for medication adherence and their practical consequences for adherence improving interventions in clinical practice.

\section{REFERENCE:}

[1] Sabate E, ed. Adherence to long-term therapies: evidence for action Geneva, World Health Organization, 2003.

[2] Nieuwlaat R, Wilczynski N, Navarro T, Hobson N, Jeffery R, Keepanasseri A, Agoritsas T, Mistry N, lorio A, Jack S, Sivaramalingam B, Iserman E, Mustafa RA, Jedraszewski D, Cotoi C, Haynes RB. Interventions for enhancing medication adherence. Cochrane Database Syst Rev. 2014; (11)

[3] Galo JS, Mehat P, Rai SK, Avina-zubieta A, Vera MA De. What are the effects of medication adherence interventions in rheumatic diseases: a systematic review. Ann rheum Dis. 2016;75: 667-673.

[4] Demonceau J, Ruppar T, Kristanto P, Hughes DA, Farger E, Kardas P, et al. Identification and assessment of adherence-enhancing interventions in studies assessing medication adherence through electronically compiled drug dosing histories: a systematic literature review and meta-analysis. Drugs. 2013;73: 545-562.

[5] Lavielle M, Puyraimond-zemmour D, Romand X, Gossec L, Senbel E, Pouplin S, et al. Methods to improve medication adherence in patients with chronic inflammatory rheumatic diseases: a systematic literature review. RMD Open. 2018;4: 1-8.

[6] Van den Bemt BJ, Zwikker HE, van den Ende $\mathrm{CH}$. Medication adherence in patients with rheumatoid arthritis: a critical appraisal of the existing literature. Expert Rev Clin Immunol. 2012;8(4):337-51.

[7] Pasma A, van't Spijker A, Hazes JM, Busschbach JJ, Luime JJ. Factors associated with adherence to pharmaceutical treatment for rheumatoid arthritis patients: a systematic review. Semin Arthritis Rheum. 2013 Aug;43 (1):18-28. doi: 10.1016/j.semarthrit.2012.12.001. Epub 2013 Jan 24.

Disclosure of Interests: Bart van den Bemt Grant/research support from: UCB Pfizer, Abbvie; Speakers bureau: Pfizer, AbbVie, UCB, Biogen, Sandoz, Consultant for: UCB, Novartis and Pfizer DOI: 10.1136/annrheumdis-2019-eular.8605

THURSDAY, 13 JUNE 2019

10:15:00 - 11:45:00

\section{Advances in understanding and treating of SLE}

\section{SP0039 WIN: DE-CONVOLUTING THE COMPLEXITIES OF SLE - RECENT INSIGHTS INTO THE PATHOGENESIS}

Mary K. Crow. Hospital for Special Surgery, Weill Cornell Medical College, Mary

Kirkland Center for Lupus Research, United States of America

Background: SLE remains one of the most complex diseases in medicine, with protean alterations in immune system function contributing to autoimmunity, tis sue inflammation and damage, and diverse clinical manifestations. While considerable advances in understanding the molecular pathways and mediators involved in SLE have led to identification of rational therapeutic targets, a ful understanding of the upstream etiologic drivers of the disease and how genetic risk and environmental stimuli shape the evolution of the disease and its clinical heterogeneity requires continued investigation.

Objectives: To review recent literature relevant to the etiology, pathogenesis and heterogeneity of SLE.

Methods: Review and synthesis of recent literature.

Results: Recent advances in characterizing the mechanisms of regulation and degradation of endogenous nucleic acids, particularly insights derived from disorders based on a variety of single gene mutations that result in production of type interferon, suggest potential drivers of type I interferon production in SLE. The functional alterations in many aspects of $T$ and $B$ cell function in patients with SLE, some attributable to type I interferon, continue to be identified. Potential contributions of the microbiome expand our view of candidate disease-enhancing factors Interest in defining patients at risk for evolving from pre-clinical to clinical disease 